\section{Minimally invasive treatment of a duodenal perforation associated with the EndoBarrier duodenal-jejunal bypass liner}

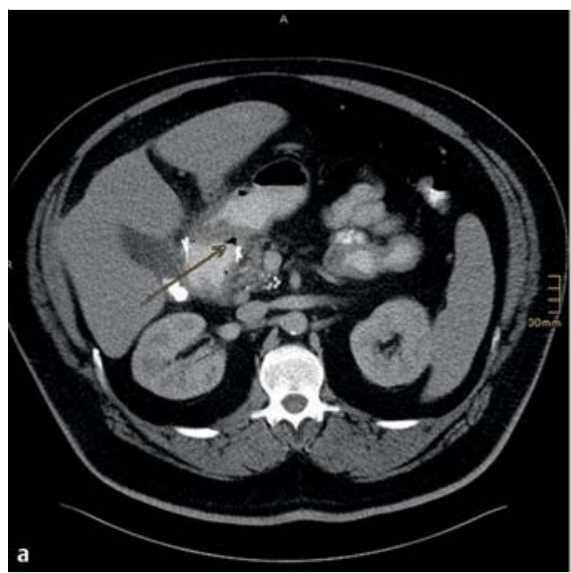

Fig. 1 Abdominal computed tomography (CT) scan in a 49-year-old man who had received a duodenal-jejunal bypass liner (DJBL) 4 weeks

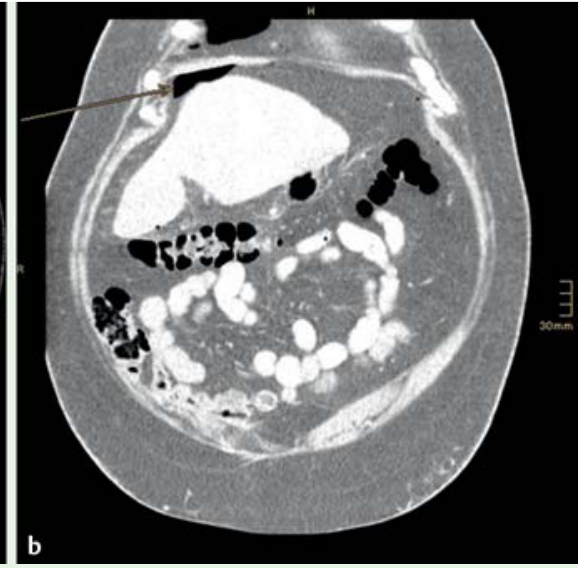

previously showing free air (arrow): a close to the nitinol anchor of the device; $\mathbf{b}$ under the right hemidiaphragm.

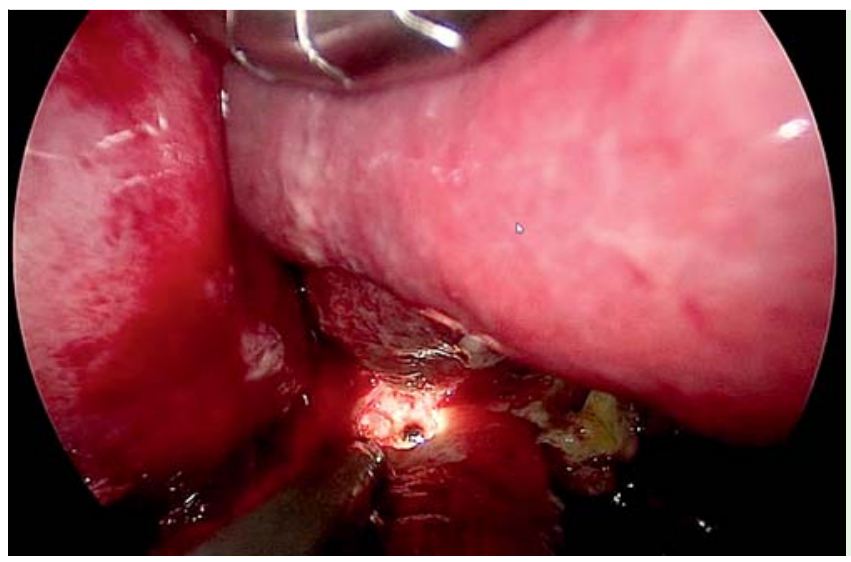

Fig. 2 Laparoscopic view of the perforation in the duodenal bulb, showing light translucency from the endoscope.

In order to establish less invasive therapies for treatment of excess bodyweight and obesity, a device that is placed endoscopically has been developed that mimics some of the anatomical and enteroendocrine effects of bariatric surgery. The EndoBarrier system (GI Dynamics, Lexington, Massachusetts, USA) is a duodenal-jejunal bypass liner (DJBL) that consists of a 60 -cm long, impermeable fluoropolymer sleeve, which is fixed in the duodenal bulb by a nitinol anchor with barbs [1]. Initial clinical studies have revealed consistent efficacy and safety, with adverse effects described as moderate or mild [1 -5]. In this case report a duodenal perforation associated with DJBL and its minimally invasive treatment were described.

A 49-year-old man received a DJBL. After 4 weeks the patient presented to the emergency department with an acute abdomen. Radiologic imaging revealed free air in the abdomen suggestive of intestinal perforation ( Fig. 1). We decided to approach this complication by a combined endoscopic and laparoscopic procedure ( Video 1). The DJBL was removed endoscopically and this was followed by laparo-

\section{Video 1}

Initially the perforation is seen in the duodenal bulb, along with light translucency from the endoscope. The perforation is closed laparoscopically with a running suture. Inspection and an air insufflation test are then used to check that the defect has been adequately closed. scopic closure of the perforation in the duodenal bulb using a running suture with self-retraining suture material (VLoc; Covidien, Dublin, Ireland; Fig.2). The patient was discharged from hospital 9 days after the surgery.

This case demonstrates a serious complication of a DJBL, which was successfully treated by an interdisciplinary team of surgeons and endoscopists. Duodenal perforation is a life-threatening event with overall mortality of approximately $8 \%$, higher in patients with accompanying risk factors [6]. The recently introduced over-the-scope clip (OTSC; Ovesco Endoscopy, Tübingen, Germany) is another option for endoscopic treatment of duodenal perforation [7].

Hereby we strongly recommend the use of minimally invasive treatment in such circumstances to preserve the options for subsequent minimally invasive metabolic surgery and reduce the perioperative risks for the patients [8]. However, if duodenal ulceration or perforation starts to be seen more frequently, the anchorage system of this device will need to be re-evaluated and revised to permit possible implantation proximal to the pylorus.

Endoscopy_UCTN_Code_CPL_1AH_2AJ

Competing interests: None

Claudia Läßle1, Katharina Laubner ${ }^{2}$, Henning Schwacha ${ }^{3}$, Jochen Seufert ${ }^{2}$, Jodok Matthias Grueneberger ${ }^{1}$, Andreas Fischer ${ }^{1}$, W. Konrad Karcz ${ }^{4}$, Ulrich T. Hopt ${ }^{1}$, Goran Marjanovic ${ }^{1}$, Simon Kuesters ${ }^{1}$

${ }^{1}$ Department of General and Visceral Surgery, University of Freiburg, Freiburg, Germany
2 Division of Endocrinology and Diabetology, Department of Internal Medicine II, University of Freiburg, Freiburg, Germany ${ }^{3}$ Division of Gastroenterology, Department of Internal Medicine II, University of Freiburg, Freiburg, Germany

${ }^{4}$ Department of Surgery, University of Schleswig-Holstein, Lübeck, Germany

\section{References}

1 Shouten R, Rijs CS, Bouvy ND et al. A multicenter, randomized efficacy study of the EndoBarrier gastrointestinal liner for presurgical weight loss prior to bariatric surgery. Ann Surg 2010; 251: 236 - 243

2 Gersin KS, Rothstein RI, Rosenthal RJ et al Open-label, sham-controlled trial of an endoscopic duodenojejunal bypass liner for 
preoperative weight loss in bariatric surgery candidates. Gastrointest Endosc 2010; 71: 976-982

3 de Moura EG, Martins BC, Lopes GS et al. Metabolic improvements in obese type 2 diabetes subjects implanted for 1 year with an endoscopically deployed duodenal-jejunal bypass liner. Diabetes Technol Ther 2012; 14: 183-189

4 Tarnoff M, Rodriguez M, Escalona $A$ et al. Open label, prospective, randomized controlled trial of an endoscopic duodenal-jejunal bypass sleeve versus low calorie diet for pre-operative weight loss in bariatric surgery. Surg Endosc 2009; 23: 650 - 656

5 Rodriguez L, Reyes E, Fagalde $P$ et al. Pilot clinical study of an endoscopic, removable duodenal-jejunal bypass liner for the treat- ment of type 2 diabetes. Diabetes Technol Ther 2009; 11: $725-732$

6 Machado NO. Management of duodenal perforation post-endoscopic retrograde cholangiopancreatography. When and whom to operate and what factors determine the outcome? A review article. JOP 2012; 13: 18 25

7 Braun A, Richter-Schrag HJ, Fischer A et al. Minimally invasive therapy of perforations at the esophagogastric junction by overthe-scope clipping. Endoscopy 2013; 45: E133-E134

8 Sekhar N, Torquati A, Youssef $Y$ et al. A comparison of 339 open and 568 laparoscopic gastric bypasses performed during a 4-year period. Surg Endosc 2007; 21: 665-668

\section{Bibliography}

DoI http://dx.doi.org/

10.1055/s-0034-1365099

Endoscopy 2014; 46: E171-E172

(c) Georg Thieme Verlag KG

Stuttgart · New York

ISSN 0013-726X

\section{Corresponding author}

\section{Claudia Läßle}

University of Freiburg

Department of General and Visceral Surgery

Hugstetter Str. 55

79106 Freiburg

\section{Germany}

Fax: +49-761-27028980

claudia.laessle@uniklinik-freiburg.de 